\title{
Exploring the Effect of Cognitive - Behavioral Counseling on Marital Satisfaction and Quality of Life Through Virtual Education
}

\author{
Ashraf Zarei Abolkheir ${ }^{1}$, Maryam Allahdadian*2, Shamila Mosharraf ${ }^{1}$, Hatav Ghasemi Tehrani ${ }^{3}$
}

1. Msc midwifery, Midwifery Department, Nursing \& Midwifery Faculty, Falavarjan branch, Islamic Azad University, Isfahan, Iran

2. Assistant Professor, Midwifery Department, Nursing \& Midwifery Faculty, Falavarjan branch, Islamic Azad University, Isfahan, Iran

3. Assistant Professor, Obstetrics and Gynecology Department, Medical Faculty, Isfahan University of Medical Sciences, Isfahan, Iran

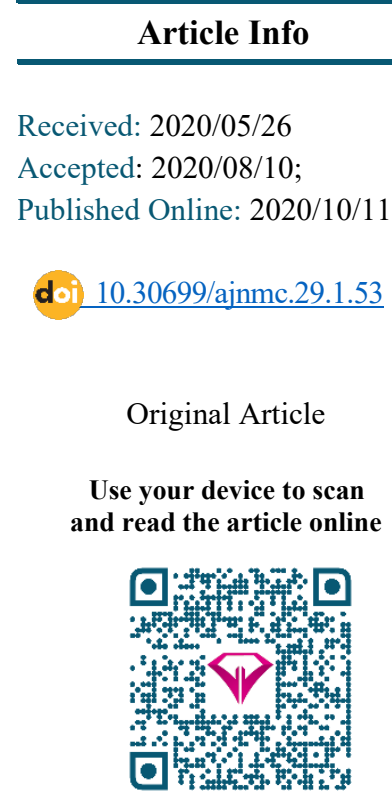

Received: 2020/05/26

Accepted: 2020/08/10

Published Online: 2020/10/11

10.30699/ajnmc.29.1.53

Original Article

Use your device to scan d read the article online

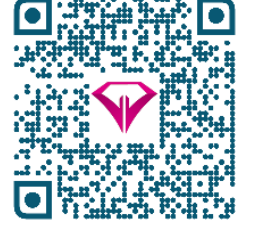

Corresponding Information:

\section{ABSTRACT}

Introduction: Infertility interferes with sexual and emotional relationships, fears of separation, feelings of isolation and depression in infertile people, and as a result has adverse effects on marital satisfaction and Quality of life. The aim of this study was to determine the effect of cognitive-behavioral counseling on marital satisfaction and Quality of life of infertile women through virtual education in Isfahan.

Methods: The present study is a Clinical trial study with the approach of an intervention group and a control that was conducted in 2018 with the participation of 60 infertile women in Isfahan. Samples were selected by available method. The intervention group received training and cognitive-behavioral counseling via WhatsApp. In this way, the samples received 30 minutes of training and counseling in 5 weeks, and their questions were answered via text message or call. The two variables of marital satisfaction and quality of life were assessed before and after the intervention. Data were analyzed by paired t-test and Covariance using SPSS 20.

Results: Based on the results, the intervention did not cause a significant change in the marital satisfaction of infertile women compared with the control group $(P=0.187)$. Based on the results, the intervention has caused a significant increase in the quality of life of infertile women compared with the control group $(P<0.001)$.

Conclusion: Although virtual education did not significantly change the marital satisfaction of infertile women compared with the control group, the average score of marital satisfaction after the intervention increased compared to the previous intervention in the subjects of the intervention group. Also, intervention through virtual education has caused a significant change in the quality of life of infertile women compared with the control group, so it seems that virtual education and counseling is useful in promoting the health of infertile women.

Keywords: Marital satisfaction, Quality of life, Virtual Education, CognitiveBehavioral Counseling, Infertility

\section{How to Cite This Article:}

Zarei Abolkheir A, Allahdadian M, Mosharraf S, Ghasemi Tehrani H. Exploring the Effect of Cognitive - Behavioral Counseling on Marital Satisfaction and Quality of Life Through Virtual Education. Avicenna J Nurs Midwifery Care. 2020; 29 (1) :53-60 
بررسى تأثير مشاورة شناختى - رفتارى بر رضايت زناشويى و كيفيت زندكى زنان نابارور بلكمك آموزش مجازى اشرف زارعى ابوالخير '، مريم الهداديان"، شميلا مشرف'، هتاو قاسمى تهرانى

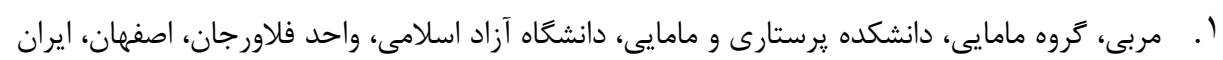

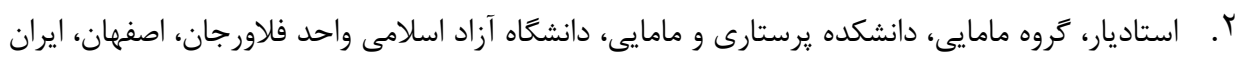

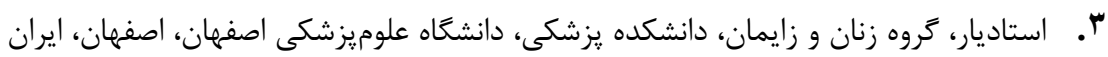

\begin{tabular}{|c|c|}
\hline 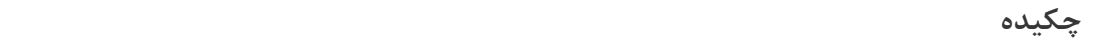 & 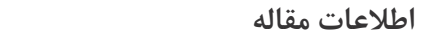 \\
\hline 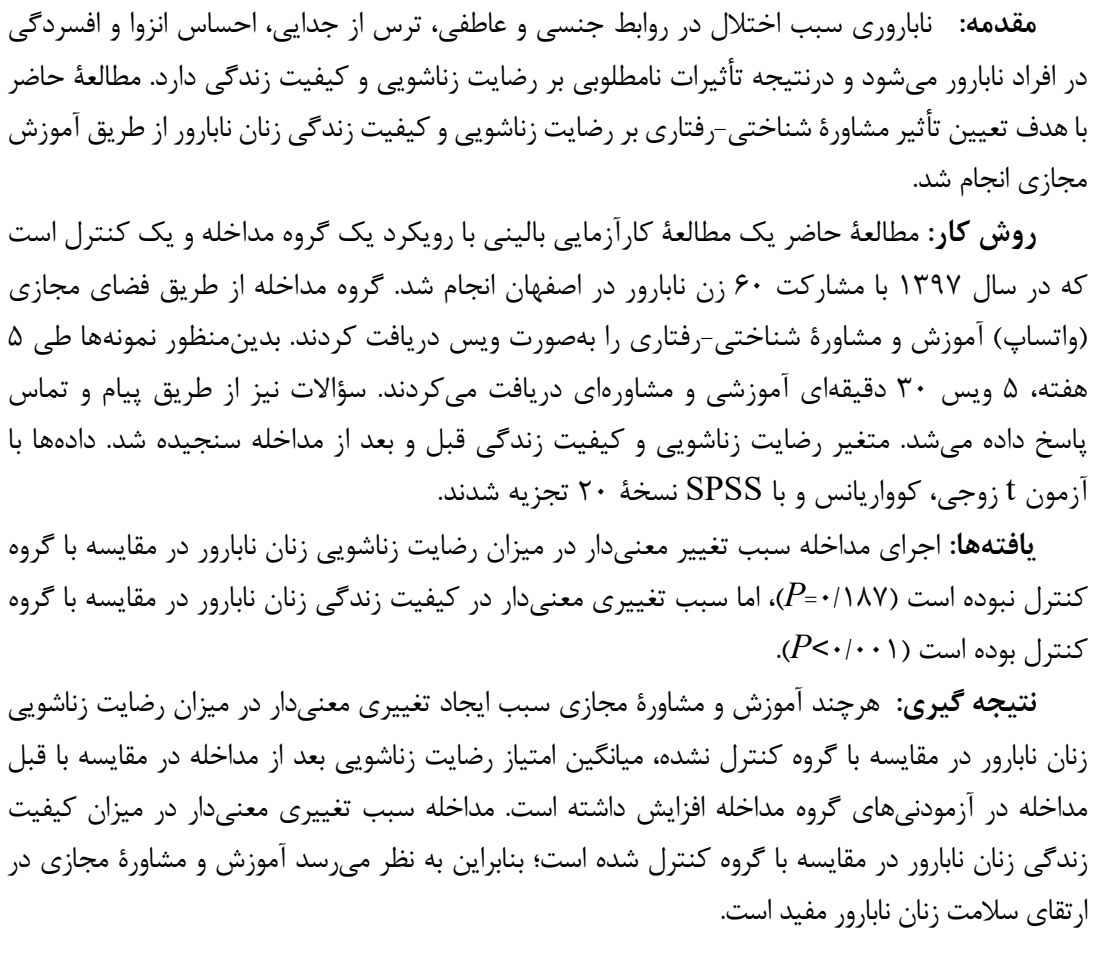 & 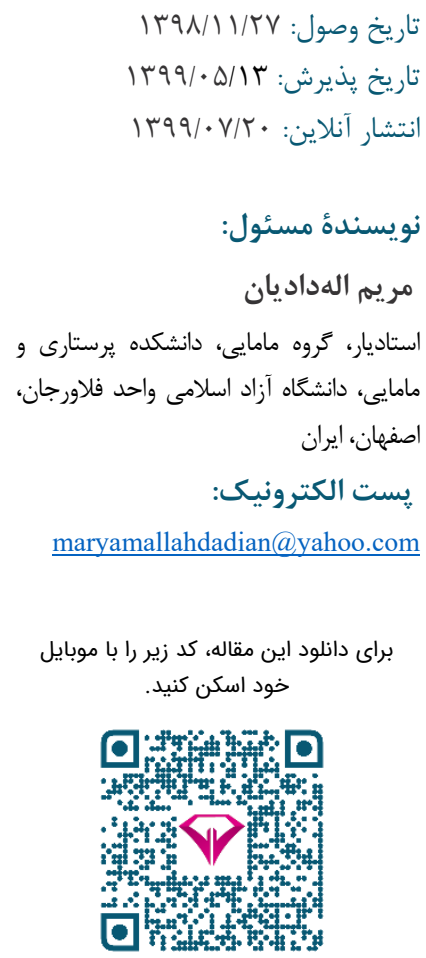 \\
\hline كليدوازهها: رضايت زناشويى، كيفيت زندگى، آموزش مجازى، مشاورة شناختى، نابارو & \\
\hline
\end{tabular}

مقدمه

مىشود [F]. زوجين نابارور در طى روند درمان با مشكلات

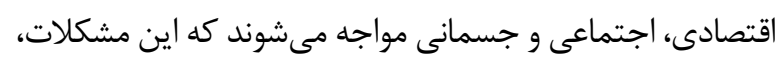

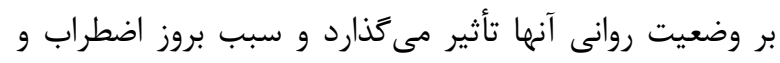

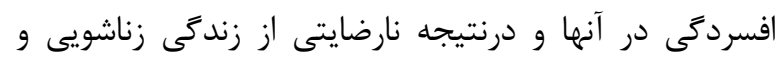

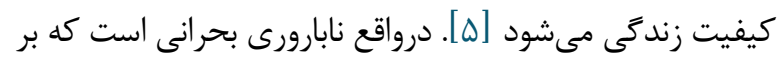

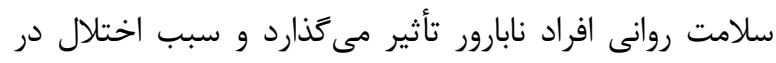
روابط جنسى، كاهش صميميت، ترس از طلاق و جدايى، كاهش ناري

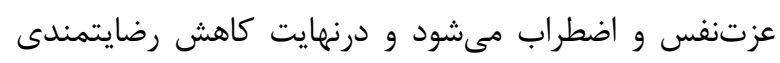

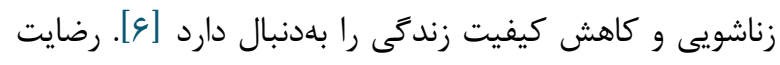

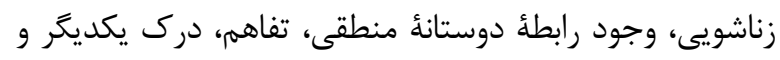

نابارورى در سراسر جهان و در همة فرهنگَها، تجربهاى

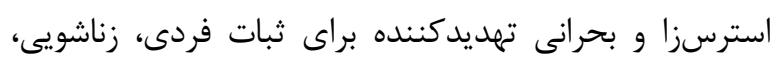

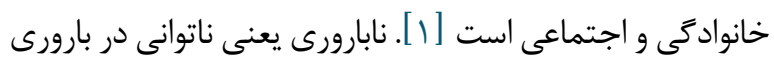

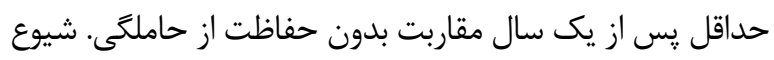

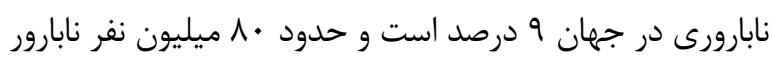

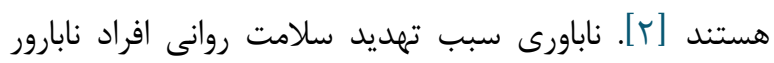

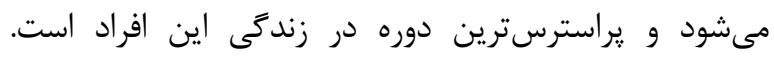

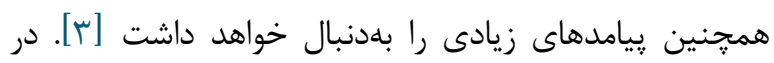

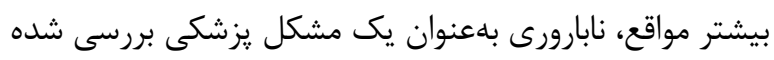

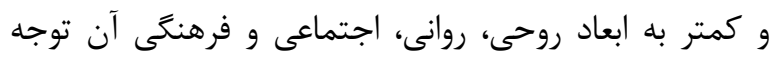


مراكز درمان نابارورى و حمايت روانى ناكافى، سبب شد تا

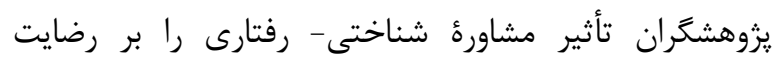

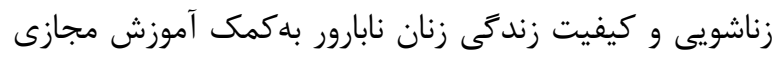

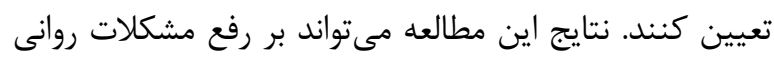
زنان نابارور و ارتقاى سلامت آنها تأثير كذار باشد.

\section{روش كار}

مطالعئ حاضر كار آزمايى بالينى با رويكرد كروه مداخله و

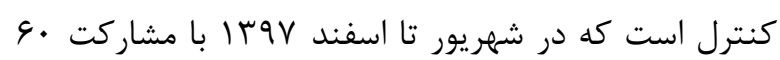

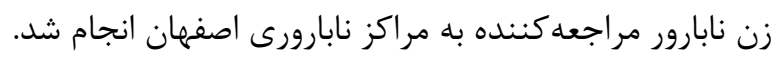

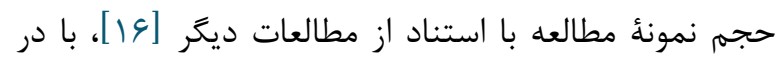

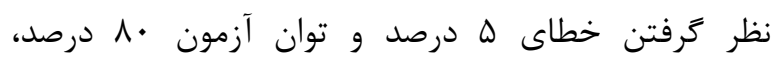

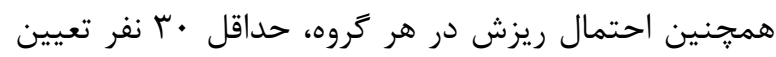

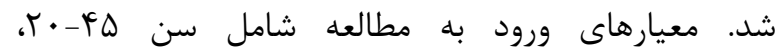
مسلمانبودن، داشتن مليت ايرانى، داشتن حداقل تحصيلات

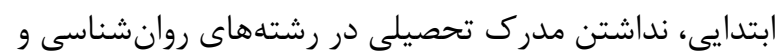
مشاوره، اعتيادنداشتن به مواد مخدر و نداشتن بيمارى شديد دريد

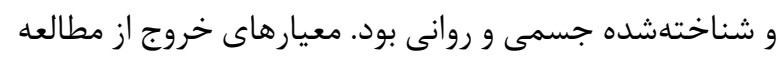

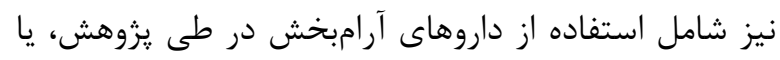
حادثٔ ناخوار طى درمان بود.

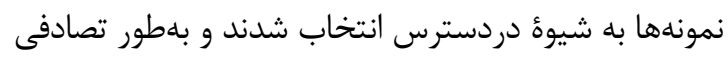

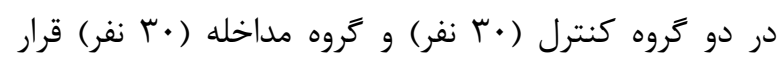

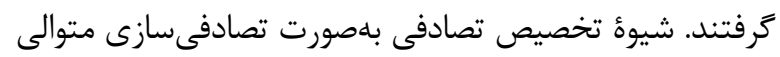

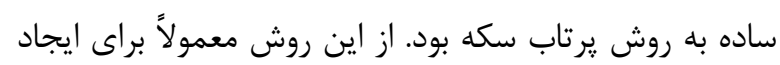

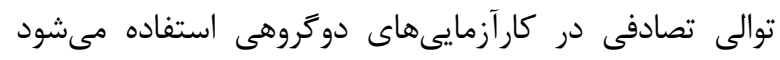

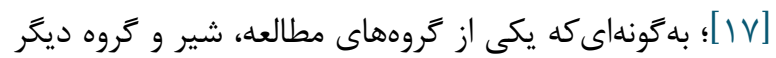
خط در نظر كرفته شدند و براساس حجم نمونهُ مورد نظر به

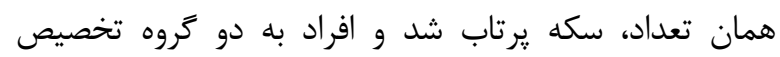

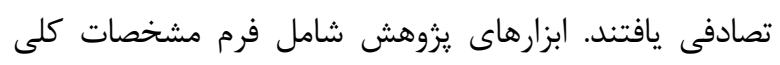
واحدهاى :ثروهش، يرسشنامة اينريج براى بررسى رضايت

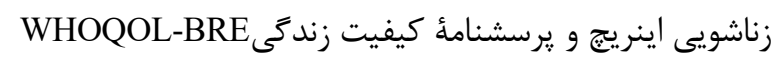

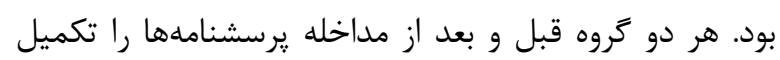
كردند. قسمت فرم مشخصات كلى واحدهاى يزوهش شامل

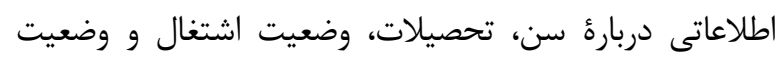

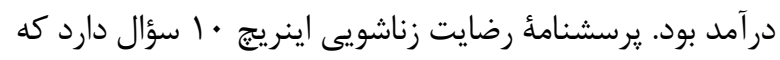

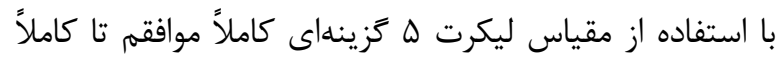

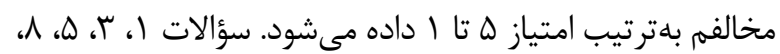

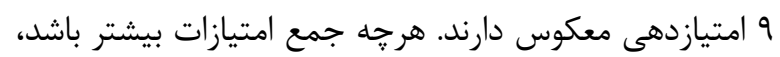

ارضاى نيازهاى مادى و معنوى زن و مرد است [V]]. درواقع

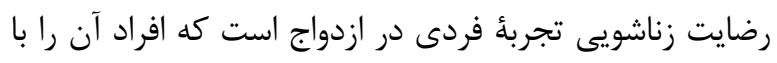

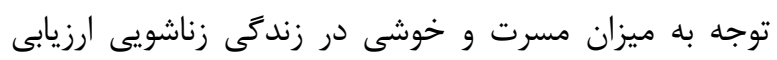

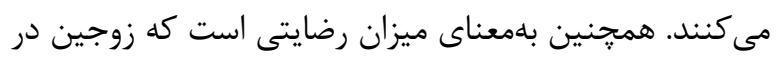

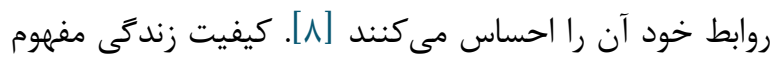
وسيعى است كه از سلامت شخص، وضعيت روانى، سطح

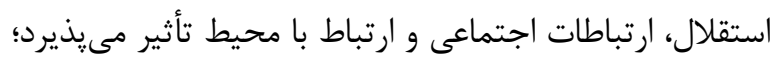

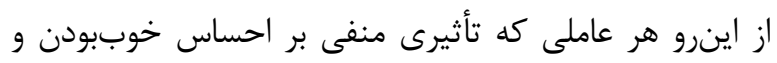

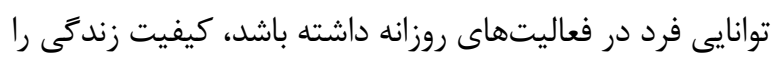

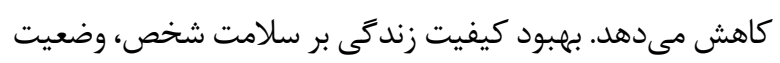

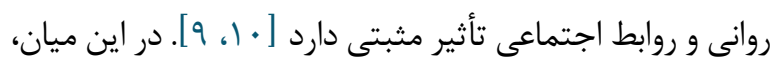

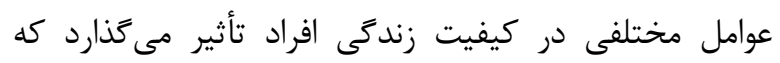

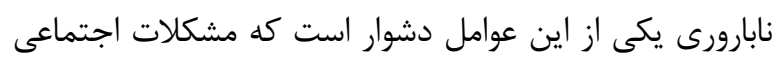

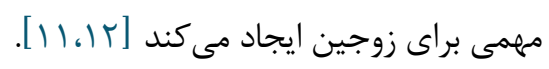

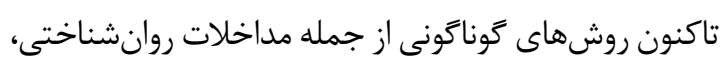

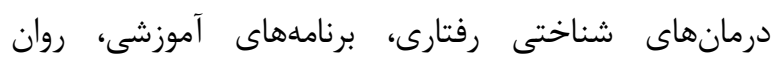

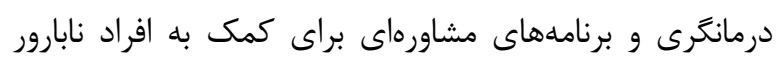

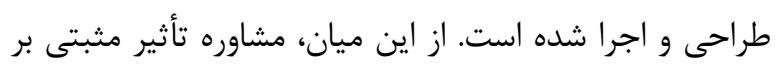

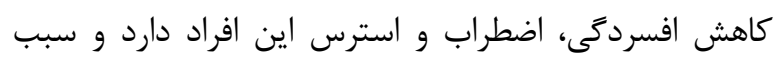

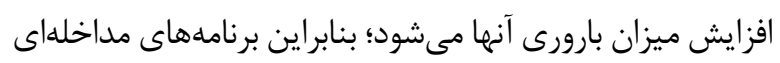

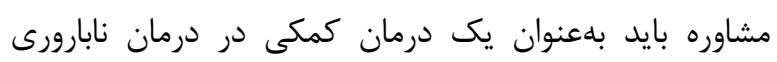

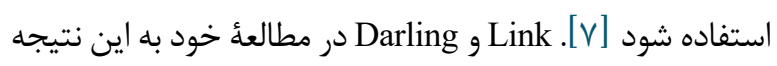

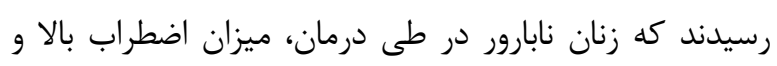

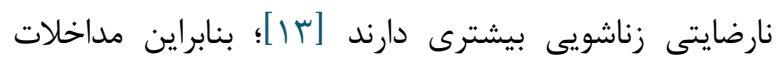

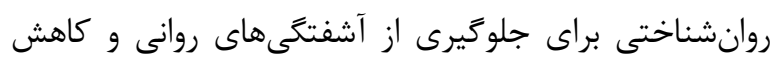

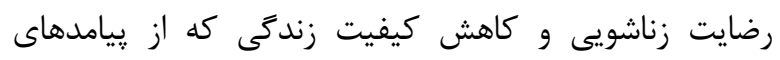

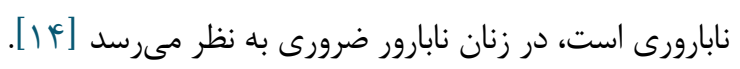

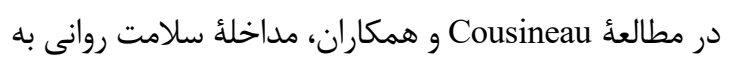

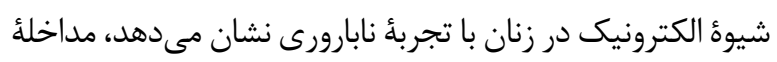

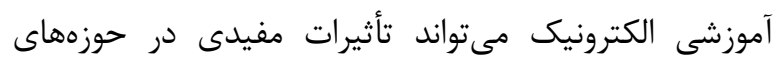

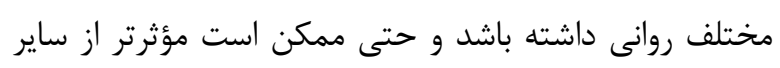

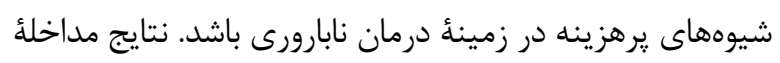

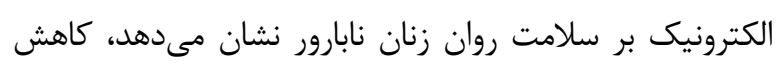

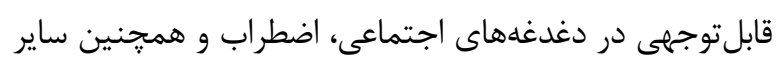

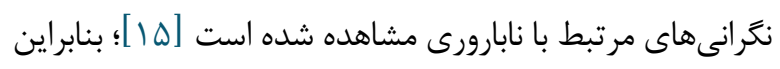
با توجه به اهميت سلامت روانى زنان نابارور، تأثير احتمالى بلى باني

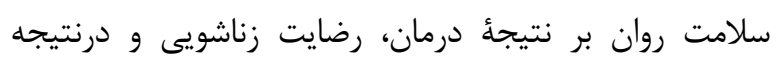
كيفيت زندگى، همجنين احساس كمبود يكى برنامه مشاوره در رضيت 
زندكى و اختلالهاى عملكرد جنسى بود و پِ از پايان از افراد خواسته شد سؤالات و نكرانىهاى خود در اين باره را با مشاور

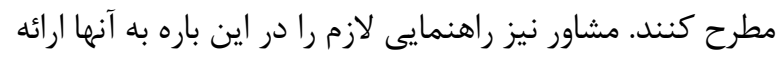

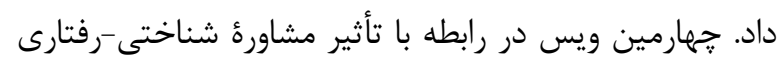
بر زندگى و كنترل استرس و اضطراب ناشى از درمان بود.

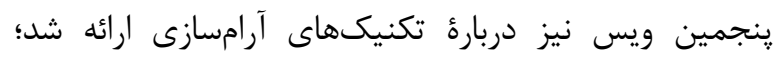

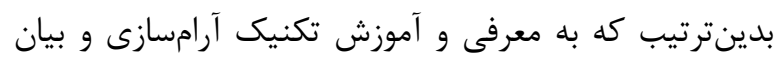

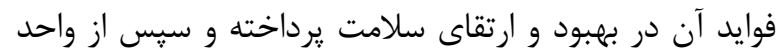
يزوهش خواسته شد تا تكنيك را در منزل انجام دهند. يك ماه

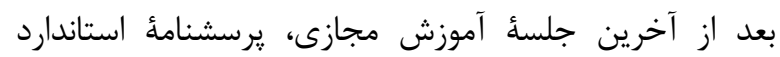

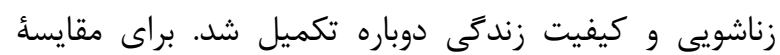

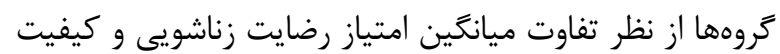

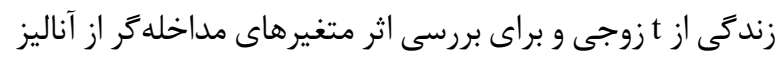

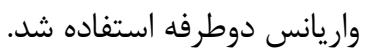
يزووهشكر يس از كسب موافقت كميتئ اخلاق دانشكاه آزاد

IR.IA اسلامى واحد

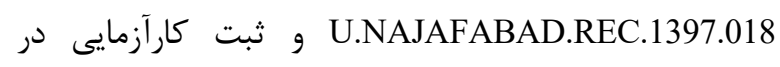
IRCTID: سايت كارآزمايى بالينى ايران و اخذ كد به شمارئ IRCT20131110015349N3

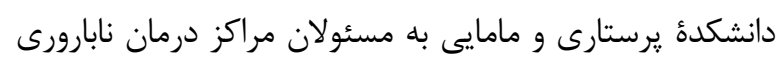

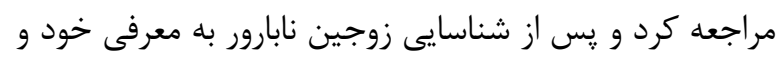
توضيح اهداف يزوهش يرداخت. معيارهاى ورود به به مطالعه

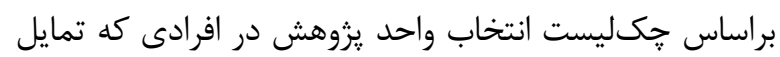

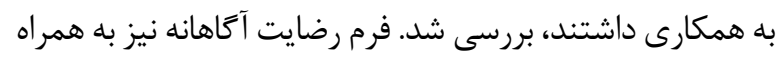
ساير :رسشنامهها در اختيار آنها قرار كرفت.

بافته ها

براساس نتايج در گروه كنترل، زنان در محدوده سنى

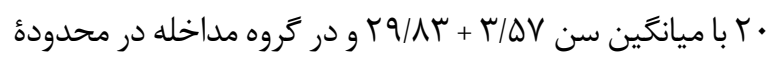

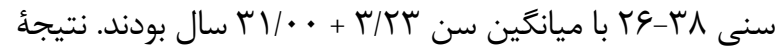
آزمون t مستقل اختلاف معنى دارى بين ميانگَين سنى دو كَروه

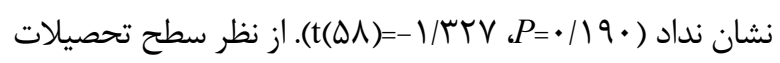
بيشترين فراوانى مشاهدهده در كل نمونه (ب// بع درصد) مربوط به زنان با تحصيلات ليسانس بود. در كروههاى كنترل

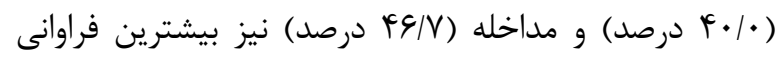
مشاهدهشه مربوط به زنان با تحصيلات ليسانس بود. نتيجئ آزمون دقيق فيشر اختلاف معنىدارى را در توزيع سطح بطان

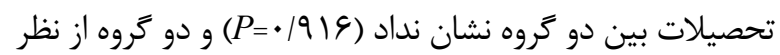

نشانهُ رضايت بيشتر از زندگى زناشويى است. روايى و يايايى در

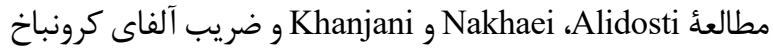

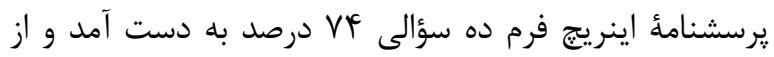

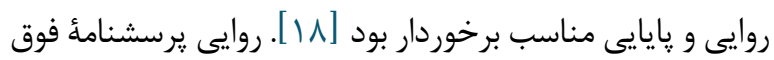
نيز به روش محتوايى و صورى بررسى شد.

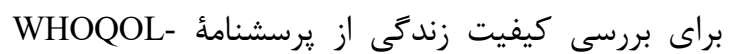

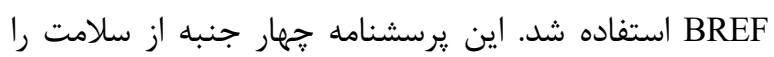

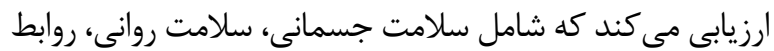
اجتماعى و سلامت محيط و حاوى أ Tؤ سؤال است (هريك از جنبههاى سلامت به ترتيب داراى ل، ؟، ب و ^ سؤال هستند).

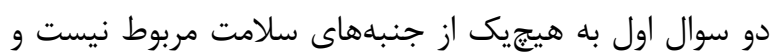
وضعيت سلامت و كيفيت زندكى را به شكل كلى مىسنجد؛

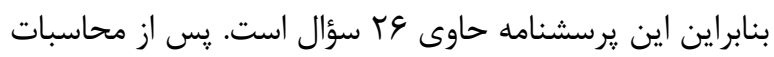

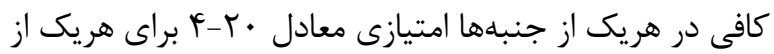
جنبههاى سلامت به تفكيك به دست آمد كه در آن امتياز

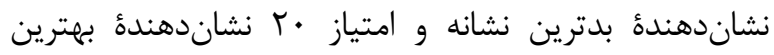

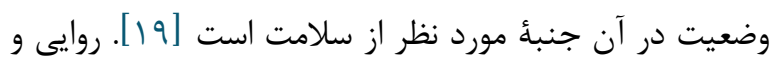

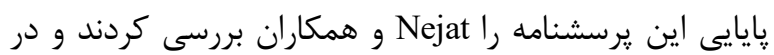

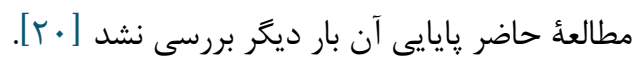

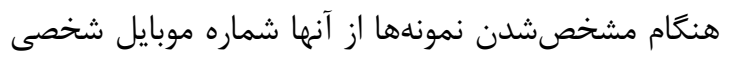
يا ايميل كرفته شد. گروه كنترل مراقبت روتين راد دريافت كردند. در كروه مداخله نيز مطالب آموزشى از طريق فضاى مجازى

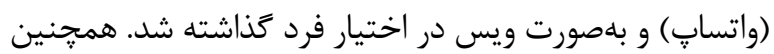

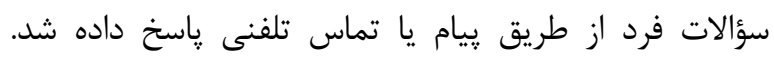

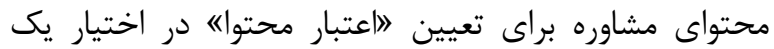
متخصص زنان و زايمان عضو هيئتعلمى دانشخاه علوم يزشكى مانى

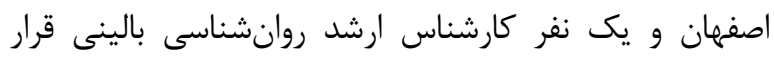
كرفت. محتوا و تعداد جلسات مشاوره براساس مطالعات قبلى

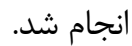
محتواى مشاوره شامل ينج ويس •r دقيقهاى بود

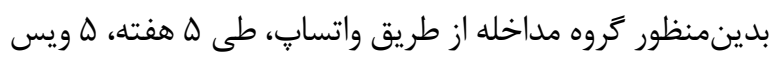

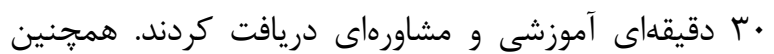

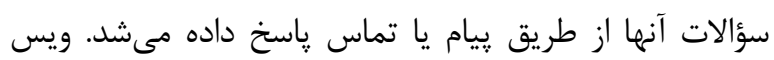

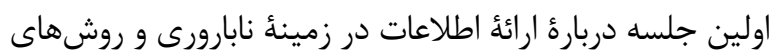

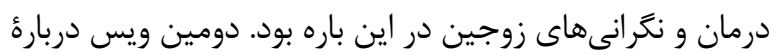

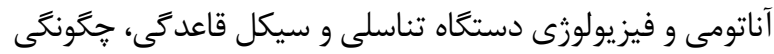
تأثير استرس و اضطراب بر تغييرات هورمونى سيستم بارورى بود. سومين ويس در رابطه با رضايت زناشويى، مفهوم كيفيت بنايت 
نداشت (آس//P=•P). همجنين در گروه مداخله امتياز رضايت

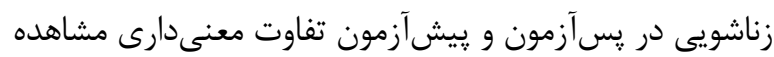

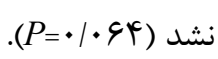

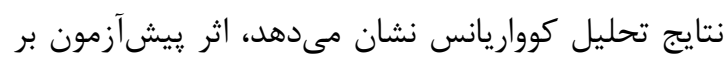
״سآزمون در سطح خطاى هإ درصد معنىدار است

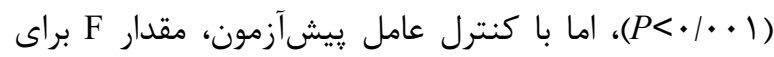

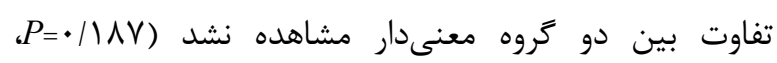
(F( (,$\Delta V)=1 / V \Lambda F$ تفاوت معنى دارى بين امتيازات رضايت زناشويى آزمودنى هاى بناى

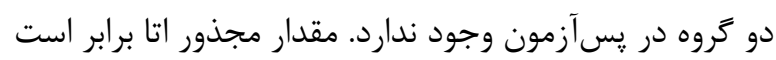

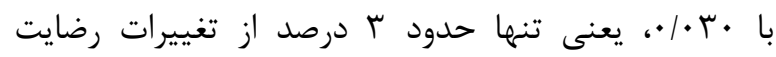
زناشويى ناشى از تفاوت در كروههاى آزمايشى است؛ بنابراين اجراى مداخله سبب ايجاد تغيير معنادار در ميزان رضايت آنائ

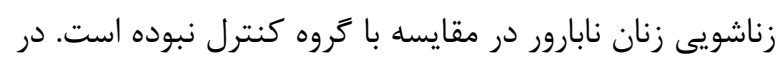
جدول 1، نتايج آناليز كوواريانس در مقايسه باريس ميا ميانكين امتياز

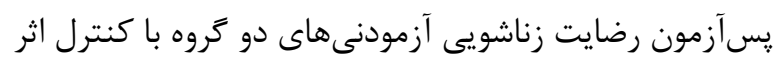

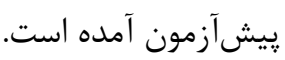

توزيع سطح تحصيلات همكن بودند. براساس نتايج، ·V درصد

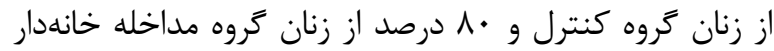

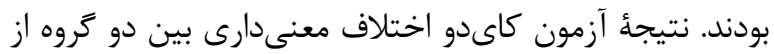

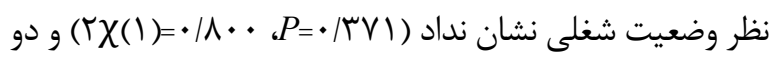
كروه از نظر توزيع شغلى همًن بودند. براساس نتايج، از نظر

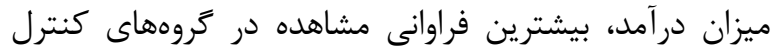

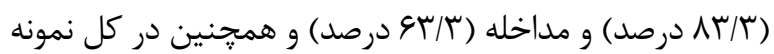

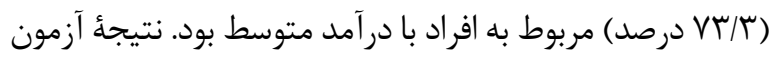
دقيق فيشر اختلاف معنىدارى بين دو تروه از نظر وضعيت

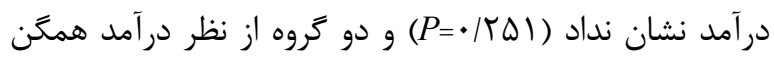
بودند. نتايج نشان مىدهد در كروه كنترل ميانخين امتياز رضايت

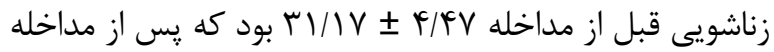
به ه/r/

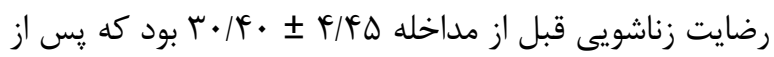

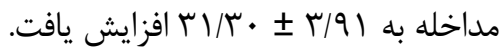
ميانگين امتياز رضايت زناشويى آزمودنىهاى كَروه كنترل

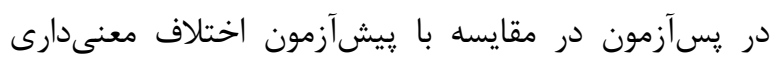

جدول ا. نتايج آناليز كوواريانس در مقايسه با ميانكَين امتياز يس آزمون رضايت زناشويى آزمودنىهاى دو تروه با كنترل اثر پيش آزمون

\begin{tabular}{|c|c|c|c|c|c|c|}
\hline مجذور اتا & سطح معنادارى & مقدار F مق & ميانكين مربعات & در جهُ آزادى & مجموع مربعات & منبع تغيير \\
\hline$\cdot|A Y|$ & $<\cdot / \cdot \bullet 1$ & $r \varepsilon / / \Delta \& V$ & $\Lambda \mid r / 9 \Delta S$ & 1 & $1 / \pi / 9 \Delta 9$ & يُش آزمون \\
\hline$\cdot / \cdot r$. & $\cdot / 1 \wedge \vee$ & IVAF & $\Delta / \Delta \Delta$. & 1 & $\Delta / \Delta \omega$. & بين كروهى \\
\hline & & & $r / 111$ & $\Delta V$ & $|V V / T|$. & خطا \\
\hline
\end{tabular}

نتايج تحليل كوواريانس نشان مىدهد اثر يیشآزمون بر

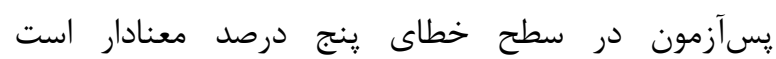

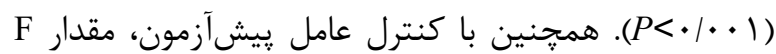

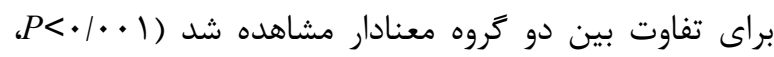

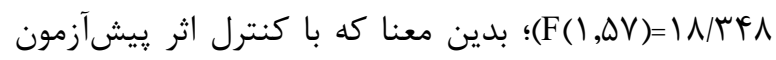

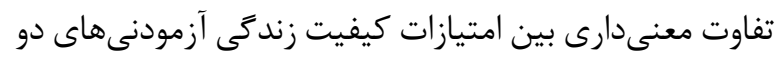

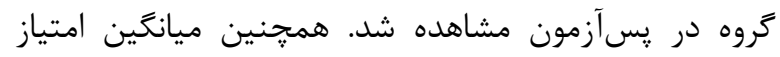

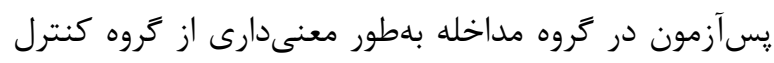

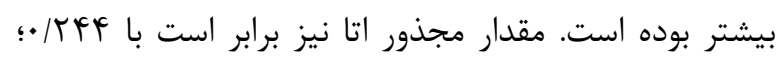

براساس نتايج، در گروه كنترل ميانگين امتياز كيفيت

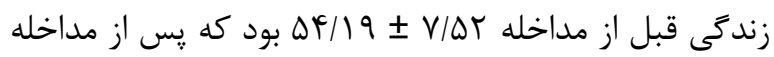

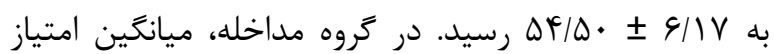

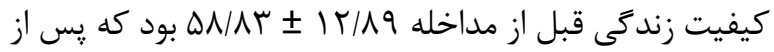
مداخله به

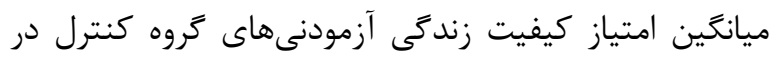

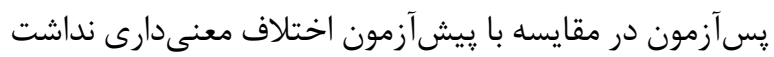
(

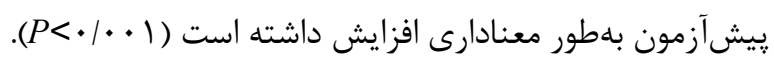


مقايسه با كروه كنترل شده است. در جدول كا، نتايج آناليز

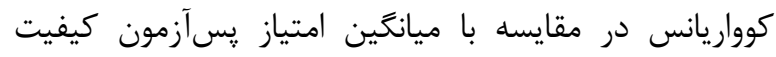
زندكى آزمودنى هاى دو گروه با كنترل اثر بيشيش آزمون آمده است.

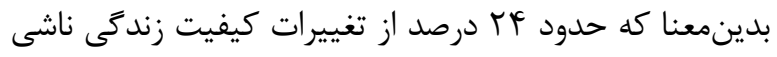

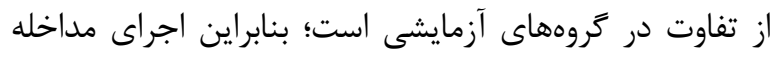

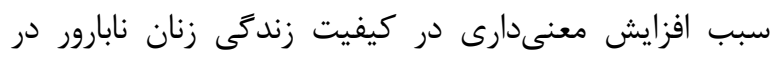

جدول r. نتايج آناليز كوواريانس در مقايسه با ميانگين امتياز يس آزمون كيفيت زندگى آزمودنىهاى دو گروه با كنترل اثر ييش آزمون

\begin{tabular}{|c|c|c|c|c|c|c|}
\hline مجذور اتا & سطح معنادارى & مقدار F & ميانگين مربعات & درجة آزادى & مجموع مربعات & منبع تغيير \\
\hline$\cdot|\Lambda| \Lambda$ & $<\cdot 1 \cdot \cdot 1$ & $r \Delta \varphi / \cdot \wedge V$ & $F q \cdot 1 / \Delta V V$ & 1 & $F G \cdot 1 / \Delta V V$ & ييش آزمون \\
\hline . MFF & $<\cdot 1 \cdot \cdot 1$ & $\mid N / T F \Lambda$ & rTq/G八F & 1 & rTq/G八F & ن خروهى \\
\hline & & & IV/9६9 & $\Delta V$ & 1. TF/TKF & خطا \\
\hline
\end{tabular}

كه نتيجه گرفتند در بررسى شيوههاى حل مسئله و سازگارى

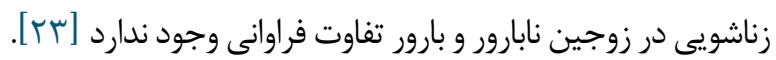

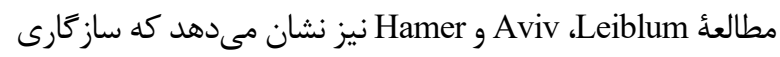
زناشويى در سه گروه IVF موفق، IVF ناموفق بدون فرزندخوانده، ناموفق با فرزندخوانده) تفاوت فراوانى نداشته است [FF مقابل مطالعات Noorbala و همكاران نشان مىدهد، درمانهاى شناختى - رفتارى نقش بسزايى در افزايش رضايتمندى زناشويى

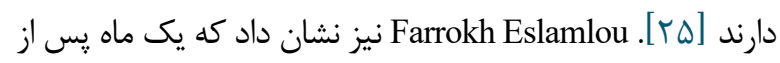
مشاوره در زروه مداخله، رضايت جنسى زنان از گروه كنترل بيشتر بود [عr]. براساس مطالعة Pizheh و Pak Gohar نيز مشاوره سبب بهبود رضايتمندى جنسى در زنان نابارور مىشود [rV]

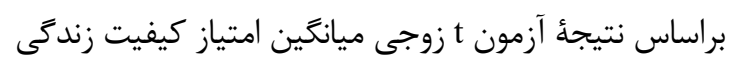

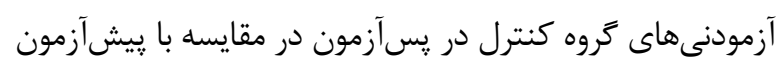

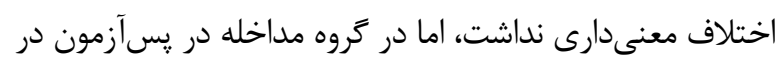

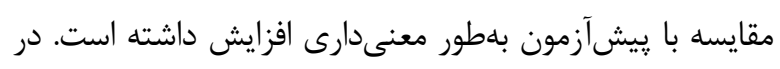

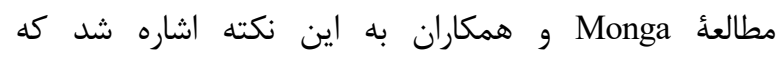
فرزنددارشدن اغلب يك توقع مهمم از ازدواج است و براى بيشتر زوجها بجهدارشدن يِامد قابلانتظار جنسى است. در اين ميان، فشارهاى اجتماعى و اطرافيان براى ادامئ نسل مى تواند سبب فشار روانى و درنتيجه كاهش رضايت زناشويى و از طرفى كيفيت

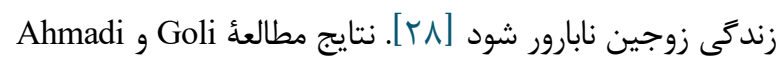

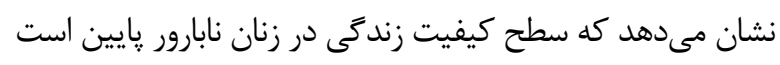
و نازايى تأثير منفى بر كيفيت زندگى اين افراد دارد [جان]. همجنين مطالعه
براساس نتايج مطالعه، هرجند ميانخين امتياز رضايت زناشويى

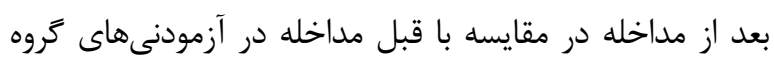
كنترل و در گروه مداخله افزايش داشته است، ميانگين امتياز

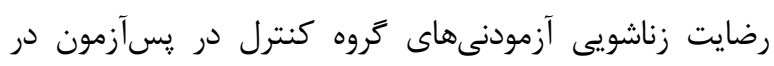
مقايسه با بيش آزمون اختلاف معنى دارى نداشته است. همجنين

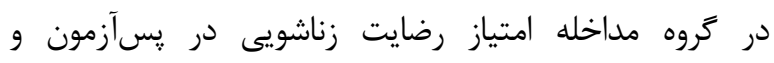
يميشآزمون تفاوت معنى دارى مشاهده نشد. همسو با اين مطالعه، Sexton مداخله مقابله با استرس نابارورى بهصورت مجازى سبب كاهش علائم مربوط به استرس عمومى زنان نابارور شده است، اما تفاوت

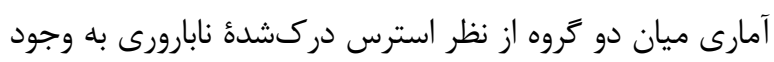

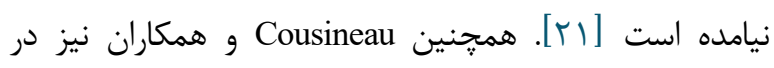
يزوهش خود نشان دادند، مداخله آموزش روانى به شيوه مجازى

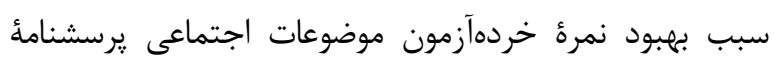
استرس نابارورى نيوتن در مقايسه با گروه كنترل نشده است

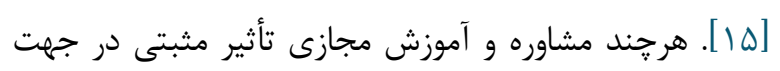

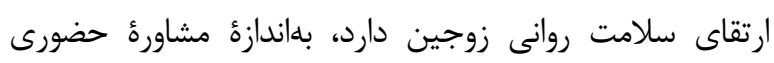
تأثير حذار نيست. درواقع با توجه به ماهيت مجازىبودن مداخله، ممكن است متغيرهاى مداخله محققان نيز خارج و بر نتيجه اثر كذار بوده است. Znoj ، Hämmerli مداخلات روانشناختى در زنان نابارور تأثيرى بر بهبود سلامت دمات

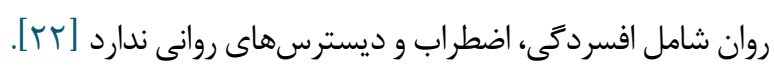
نتايج مطالعة حاضر همسو با مطالعه 


$$
\text { كضفيت مراقبت انجام گيرد. نتايج اين مطالعه مىتواند موجب ارتقاى }
$$

$$
\text { سياسگز ارى }
$$

از معاونت يزوهشى دانشگاه آزاد ڤيرستارى و مامايى

فلاورجان بلهدليل تصويب و حمايت مالى با شماره ثبت

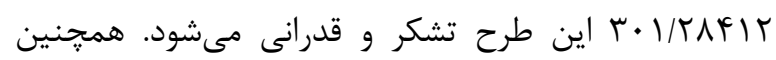

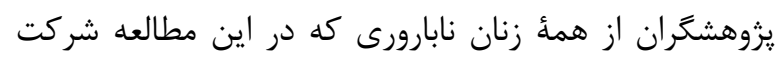

كردند، مسئولان محترم مراكز نابارورى اصفهان و همة عزئن عزيزانى

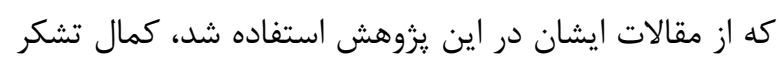

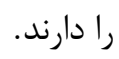

$$
\text { تعارض در منافع }
$$

بين نويسندَان هيجَّونه تعارضى در منافع وجود ندارد

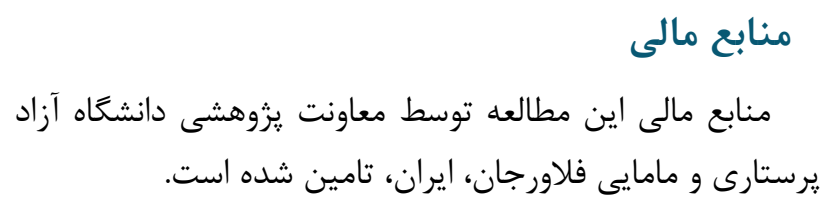

\section{References}

1. Bushnik T, Cook JL, Yuzpe AA, Tough S, Collins J. Estimating the prevalence of infertility in Canada. Hum Reprod. $2012 \quad$ Mar 1;27(3):738-46. [DOI:10.1093/humrep/der465] [PMID] [PMCID]

2. Boivin J, Bunting L, Collins JA, Nygren KG. International estimates of infertility prevalence and treatment-seeking: potential need and demand for infertility medical care. Hum Reprod. 2007;22(6):150612. [DOI:10.1093/humrep/dem046] [PMID]

3. De Berardis D, Mazza M, Marini S, Del Nibletto L, Serroni N, Pino MC, Valchera A, Ortolani C, Ciarrocchi F, Martinotti G, Di Giannantonio M. Psychopathology, emotional aspects and psychological counselling in infertility: a review. Clin Ter. 2014;165(3):163-9.

4. Haririan HR, Mohammadpour Y, Aghajanloo A. Prevalence of depression and contributing factors of depression in the infertile women referred to Kosar infertility center, 2009. Iranian Journal of Obstetrics, Gynecol Infertil. 2010;13(2):45-9.

5. Hasanpoor-Azghdy SB, Simbar M, Vedadhir A. The emotional-psychological consequences of infertility among infertile women seeking treatment: Results of a qualitative study. Iran J Reprod Med. 2014;12(2):131.

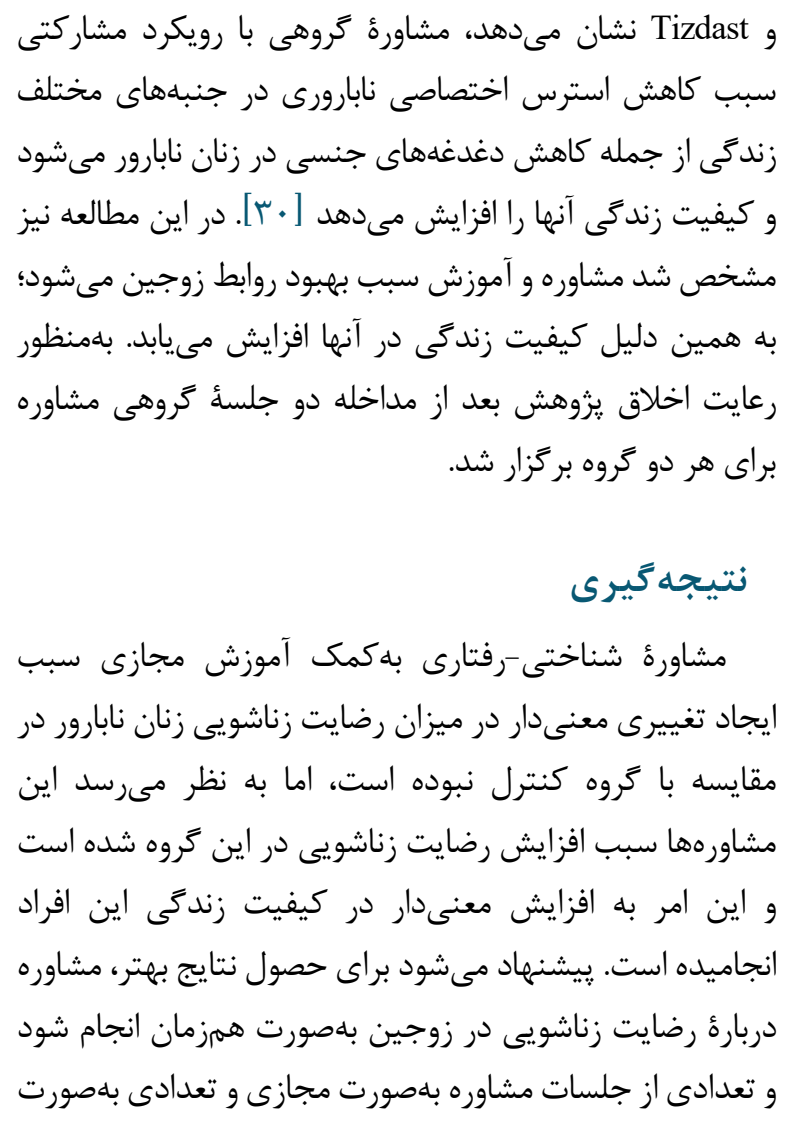

6. Terzioglu F, Turk R, Yucel C, Dilbaz S, Cinar O, Karahalil B. The effect of anxiety and depression scores of couples who underwent assisted reproductive techniques on the pregnancy outcomes. African Health Sci. 2016;16(2):441-50. [DOI:10.4314/ahs.v16i2.12] [PMID] [PMCID]

7. Behdani F, Erfanian M, Hebrani P, Hojat SK. Prevalence of depression and related factors in infertile women referred to Montaserie infertility clinic in Mashhad. J Fundam Ment Health.2005; 23\&24:141-146

8. Solati K, Lo'Bat Ja'Farzadeh AH. The effect of stress management based on group cognitive-behavioural therapy on marital satisfaction in infertile women. J Clin Diagn Res. 2016;10(7):VC01. [DOI:10.7860/JCDR/2016/17836.8077] [ [PMCID]

9. Clayton D. Correlates of quality of life patient with MS. Rehab Nursing. 1995;19:634-7.

10. Cella DF. Quality of life: concepts and definition. J Pain Symp Manag. 1994;9(3):186-92. [DOI:10.1016/08853924(94)90129-5]

11. Yaghmaei F, Mohammadi S, Majd HA. Developing" quality of life in infertile couples questionnaire" and 
measuring its psychometric properties. J Reprod Infertil. 2009;10(2).

12. Moura-Ramos M, Gameiro S, Canavarro MC, Soares I. Assessing infertility stress: re-examining the factor structure of the Fertility Problem Inventory. Hum Reprod. 2012 Feb 1;27(2):496-505. [DOI:10.1093/humrep/der388] [PMID]

13. Link PW, Darling CA. Couples undergoing treatment for infertility: Dimensions of life satisfaction. J Sex Marital Ther. 1986;12(1):46-59. [DOI:10.1080/00926238608415393] [PMID]

14. Shokrollahzadeh M, Forouzesh M, Hosseini H. The effect of cognitive behavioral couple therapy on marital conflicts and marital burnout. Family Pathology, Counseling and Enrichment Journal. 2017;3(1):115-31.

15. Cousineau TM, Green TC, Corsini E, Seibring A, Showstack MT, Applegarth L, Davidson M, Perloe M. Online psychoeducational support for infertile women: a randomized controlled trial. Hum Reprod. 2008;23(3):554-66. [DOI:10.1093/humrep/dem306] [PMID] [PMCID]

16. Mohammady M, Janani L. [Randomization in randomized clinical trials: From theory to practice]. Hayat, Journal of School of Nursing and Midwifery, Tehran Uni Med Sci. 2016; 22(2): 102-114.

17. Latifnejad Rudsari R, Rasoulzadeh Bidgoli M, Mousavifar N, Modares Gharavi M. Investigating the effect of infertility participatory counseling on perceived stress in infertile women treated with IVF. Iran J Obstet, Gynecol Infertil. 2011; 14 (4): 22-31.

18. Alidosti A., Nakhaei N, Khanjani N. Reliability and validity of Kansas and Inrich marriage questionnaires abbreviated in Persian. J Health Dev. 2015; 4(2): 167158

19. WHOQOL-BREF WH. Introduction, Administration, Scoring and Generic Version of the Assessment-Field Trial Version. Geneva, Switzerland. 1996.

20. Nejat SA, Montazeri A, Holakouie Naieni K, Mohammad KA, Majdzadeh SR. The World Health Organization quality of Life (WHOQOL-BREF) questionnaire: Translation and validation study of the Iranian version. Journal of School of Public Health and Institute of Public Health Research. 2006;4(4):1-2.

21. Sexton MB, Byrd MR, O'Donohue WT, Jacobs NN. Web-based treatment for infertility-related psychological distress. Arch Womens Ment Health. 2010;13(4):347-58. [DOI:10.1007/s00737-009-0142-x] [PMID]

22. Hämmerli K, Znoj H, Barth J. The efficacy of psychological interventions for infertile patients: a meta-analysis examining mental health and pregnancy rate. Human Reprod Update. 2009;15(3):279-95. [DOI:10.1093/humupd/dmp002] [ㅍID]

23. Mazaheri MA, Kayghobadi F, Imani ZF, Ghashang N, Pato M. Problem solving strategies and marital adjustment in infertile and fertile couples. J Reprod Infertil. 2001;8(2):22-23.
24. Leiblum SR, Aviv A, Hamer R. Life after infertility treatment: a long-term investigation of marital and sexual function. Human reproduction (Oxford, England). 1998;13(12):3569-74. [DOI:10.1093/humrep/13.12.3569] [PMID]

25. Noorbala AA, Ramezanzadeh F, Malakafzali H, Abedinia N, Rahimi Foroushani A, Shariet M. Effectiveness of psychiatric interventions on depression rate in infertile couples referred to Vali-Asr. Hakim Res J. 2008;10(4):17-26.

26. Farrokh Eslamlou HR, Hajishafiha M, Kazemi ES, Oshnouei S. Impact of primary infertility on life quality in Urmia, Iran. J Urmia Univ Med Sc. 2014;25(7):598604.

27. Vizheh M. Pak Gohar M. Rouhi M. Veisy A. Impact of Gender Infertility Diagnosis on Marital Relationship in Infertile Couples: A Couple Based Study. Sexuality and Disability. 2015;33(4) :457-468. DOI: 10.1007/s11195015-9417-5 [DOI:10.1007/s11195-015-9417-5]

28. Monga M, Alexandrescu B, Katz SE, Stein M, Ganiats T. Impact of infertility on quality of life, marital adjustment, and sexual function. Urology. 2004;63(1):126-30. [DOI:10.1016/j.urology.2003.09.015] [PMID]

29. Goli M, Ahmadi S. Quality of Life and Its Related Factors in Infertile Women of Isfahan 2008. Sci J Ilam Uni Med Sci. 2012;20(3):63-70.

30. Hamzeh Pourhaghighi T, Ghorban Shiroodi Sh, Tizdast $\mathrm{T}$, The Effect of Cognitive Behavioral Therapy on the Reduction of Anxiety in Infertile Women. Eu J Exp Biol.2009;2(5):415-419. 